\title{
Prophylactic colectomy and rectal preservation in FAP: systematic endoscopic follow-up and adenoma destruction changes natural history of polyposis $\square$
}

\section{(ㄷ)(i) $\Theta$}

Authors

Arnaud Pasquer ${ }^{1,2}$, Nicolas Benech ${ }^{3}$, Mathieu Pioche ${ }^{2,3}$, Antoine Breton ${ }^{1}$, Jerome Rivory ${ }^{3}$, Olivier Vinet ${ }^{3}$, Gilles Poncet $^{1,2}$, Jean Christophe Saurin ${ }^{2,3}$

Institutions

1 Digestive and Oncological Surgery Department, Edouard Herriot Hospital, Hospices Civils de Lyon, Lyon, France

2 University Claude Bernard Lyon I, Faculté de Médecine Lyon Est, Lyon, France

3 Hepato-gastroenterology Department Edouard Herriot Hospital, Hospices Civils de Lyon, Lyon, France

submitted 23.2.2021

accepted after revision 4.3.2021

Bibliography

Endosc Int Open 2021; 09: E1014-E1022

DOI 10.1055/a-1467-6257

ISSN 2364-3722

(C) 2021. The Author(s).

This is an open access article published by Thieme under the terms of the Creative Commons Attribution-NonDerivative-NonCommercial License, permitting copying and reproduction so long as the original work is given appropriate credit. Contents may not be used for commercial purposes, or adapted, remixed, transformed or built upon. (https://creativecommons.org/licenses/by-nc-nd/4.0/)

Georg Thieme Verlag KG, Rüdigerstraße 14,

70469 Stuttgart, Germany

Corresponding author

Dr Arnaud Pasquer, MD, Department of Digestive and

Colorectal Surgery, Edouard Herriot University Hospital,

5 place d'Arsonval, 69003 Lyon, France

Arnaud.pasquer@chu-lyon.fr

\section{ABSTRACT}

Background and study aims Prophylactic surgery of familial adenomatous polyposis (FAP) includes total colectomy with ileorectal anastomosis (IRA) to proctocolectomy with ileoanal anastomosis (IAA). Surgical guidelines rely on studies without systematic endoscopic follow-up and treatment. Our aim was to report our experience based on a different approach: therapeutic follow-up, comparing in this setting IRA and IAA in terms of oncological safety and quality of life.

Patients and methods Between January 1965 and November 2015, all patients who underwent prophylactic surgery for FAP with therapeutic endoscopic follow-up in Lyon University hospital: systematic endoscopic treatment of adenomas, were retrospectively and prospectively (since 2011) included.

Results A total of 296 patients were analyzed: 92 had proctocolectomy with IAA (31.1\%), 197 total colectomy with IRA (66.5\%), and seven abdominoperineal resections (2.4\%). Median follow-up was 17.1 years (range, $0-38.1$ ). Incidence of secondary cancer (IR vs. IAA) was $6.1 \%$ vs. $1.1 \%(P=0.06$; $95 \% \mathrm{Cl} 0.001-0.36)$. The 15-year cancer-free and overall survival (IR vs. IAA) were $99.5 \%$ vs $100 \%(P=0.09)$ and $98.9 \%$ vs. $98.8 \%(P=0.82)$, respectively. Postoperative morbidity occurred in 44 patients: $29(14.7 \%)$ in the IRA and 15 (16.3\%) in the IAA group $(P=0.72)$. The mean number of stools per day in the respective groups were $4.4(2.5)$ vs. $5.5(2.6)(P=0.001)$. Fecal incontinence occurred in 14 patients $(7.1 \%)$ in the IRA vs. $16(17.4 \%)$ in the IAA group ( $P$ $=0.03)$.

Conclusions A combination of therapeutic endoscopic treatment and extended rectal preservation appears to be a safe alternative to ileoanal J-pouch anastomosis.

\section{Introduction}

Familial adenomatous polyposis (FAP) is strongly associated with the occurrence of colorectal cancer [1]. The specificities of FAP are management at young age; the specific prophylactic surgical treatment including total colectomy with ileorectal anastomosis (IRA) or proctocolectomy with ileoanal anastomosis and J pouch (IAA). Recent guidelines report a mean age at surgery of 20 years [2]. Rectal preservation is usually recommended when preoperative workup finds fewer than five rectal adenomas; proctectomy remains the gold standard when $>20$ adenomas are found. 
Proctocolectomy is justified by relatively old series that found secondary rectal cancer rates of $11.2 \%$ at 15 years and $13 \%$ to $59 \%$ at 25 years $[3,4]$. However, in this young population who will undergo mutilating procedures, postoperative quality of life is a major issue. To date, the main difference between these two strategies is poorer quality of life with social impairment related to IAA, such as incontinence and an increased number of stools per day. Thanks to the technical improvements of endoscopy, a different approach has been adopted in the Lyon university hospital and relies on systematic endoscopic destruction or resection of residual adenomas in the rectal stump, allowing for a more conservative attitude. This was possible because of the development of Nd-Yag laser coagulation in the 1980s, then the development of argon plasma coagulation in the 1990s, and cold snare resection today. In the context of this new aggressive endoscopic approach, the main objective of our study was to describe the long-term risk of rectal/pouch cancer. Secondary objectives were to describe morbidity related to surgery or to endoscopy and long-term quality of life according to functional results.

\section{Patients and methods}

\section{Databases}

Data were extracted from a dedicated national database (plateforme d'échange entre personnels de santé; clinicaltrials.gov NCT01987518) created in January 2011, and included genetic identification and prospectively-recorded endoscopic followup [5]. Data for patients followed before 2011 were retrospectively entered using surgical and endoscopic databases.

\section{Study population}

All patients with FAP diagnosis who underwent prophylactic and/or curative surgery in three university hospitals of the Rhône-Alpes region of France (Lyon, Grenoble, and Saint Etienne) between January 1965 and November 2015 were retrospectively (before 2011) or prospectively (2011 and later) included. Endoscopic follow-up was performed until 2020. Diagnosis of FAP was based on genetic identification of known mutations: exons $1,4,5,6,7,9,10,11,13,14,15$; introns $6,7,9$, 10, 14; locus DP1, delq15q23, and total deletion. When genetic analysis and/or patients refused genetic analysis, or when genetic analysis failed to identify any mutation, the diagnosis of FAP was based on classical clinical criteria: diffuse polyposis of the colon and/or rectum, confluent adenomas in patients aged $<20$ years. Patients for whom endoscopic/pathological data were not available during follow-up, synchronous metastases, or who benefited from abdominoperineal resection (APR), were excluded from the analysis.

\section{Data collection}

Demographic information (age, sex, tumor location when present at diagnosis: colic and/or rectal, comorbidities, previous surgical history, and known pathogenic variants) was recorded. As recommended by the French guidelines [2], clinical staging included endoscopic colorectal examination to evaluate colon/ rectum adenoma number to determine surgical indication. For patients without detailed colonic adenoma count, as endoscopic descriptions were standardized in the three centers, profuse polyposis in each segment was interpreted as $>100$ adenomas, moderate as 50 , and poor as five polyps. Total colectomy with IRA and coloproctectomy with IAA and J pouch were performed. Surgery consisted of laparoscopic or open en bloc total colectomy or proctocolectomy, with nodal resection when surgery was performed in case of primary cancer, or high-grade dysplasia/intramucosal carcinoma; no nodal resection in case of low-grade adenomas [1,2]. Operative techniques were open and laparoscopic approaches.

\section{Surgical indications}

Current guidelines recommend that prophylactic surgery be performed according to age and endoscopic findings [1,2]. Guidelines are quite unclear (up to 20 for Sinha and al) regarding the upper limit of the rectal polyp number justifying proctectomy. In accordance to international practices and local guidelines (based on clinical observation), rectal preservation was preferred, independently of adenoma number if endoscopic treatment of rectal adenomas was estimated to be feasible and safe by a trained endoscopist (expert in FAP management). This included biopsies revealing benign adenomas with low- or high-grade dysplasia (Vienna 3 or 4.1), and/or intra mucosal cancer (Vienna 4.2 to 4.4 ) if complete and carcinologic resection was achieved. When expert endoscopists estimated that the rectal disease was not accessible to endoscopic treatment or if patients were not willing to undergo close followup, proctectomy was performed. In cases of advanced primary cancer, oncological surgery was proposed. In case of colonic cancer, total colectomy with IRA was performed, and for rectal cancer, proctocolectomy with IAA or perineal resection was performed.

\section{Follow-up, endoscopic treatment, and secondary cancer occurrence}

A follow-up regimen of clinical examination and postoperative lower endoscopy was recommended 6 months after surgery then at least annually in case of IRA, and biennially in case of IAA. In case of excellent control in the rectal stump (few residual adenomas and low-grade dysplasia), the follow-up interval could be extended to every 2 years in IRA patients [6]. During endoscopy, systematic treatment of remaining or newly devel-

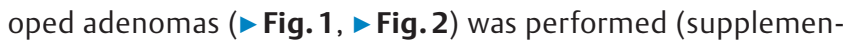
tary materials). Small lesions ( $\leq 5 \mathrm{~mm}$ ) were treated using argon plasma coagulation (40 W) [6]. Alternatives were cold-snare biopsy, endoscopic mucosectomy, and submucosal dissection ( $\triangleright$ Fig. 3 and $\triangleright$ Video 1 ). In cases of diffuse polyposis (> 100 lesions) in the rectal stump or pouch, a multistep treatment was proposed with therapeutic lower endoscopies at an interval of 2 to 3 weeks. When completely treated, follow-up endoscopies were performed every 6 months until rectal adenoma clearance. Further endoscopic follow-up was progressively extended from every 6 months to yearly surveillance to reach the standard follow-up frequency. Diagnosis of secondary cancer was based on histologically proven relapse of cancer within the rectum or the J pouch, including local anastomotic sites. As this re- 


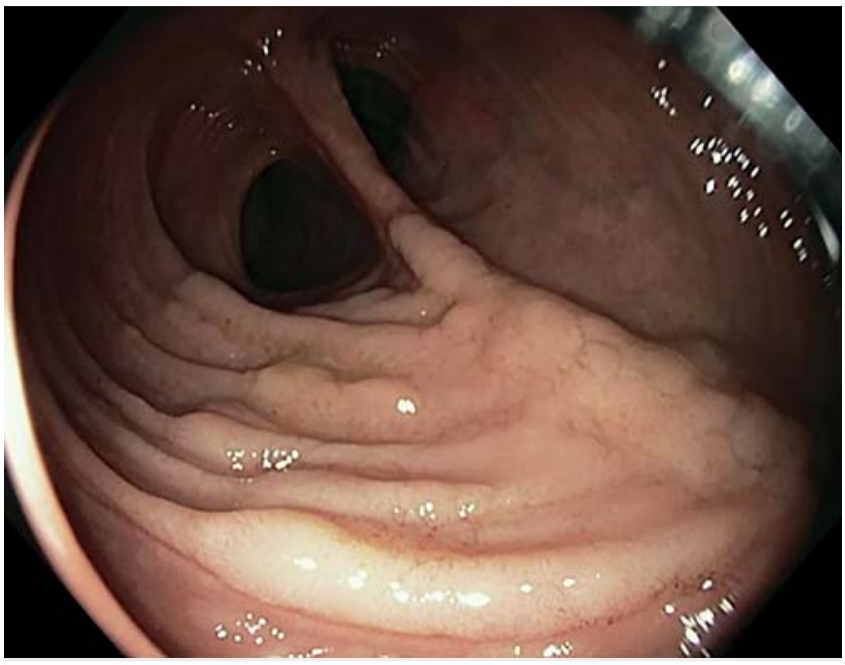

- Fig. 1 lleal pouch with multiple flat adenomas without chromoscopy.

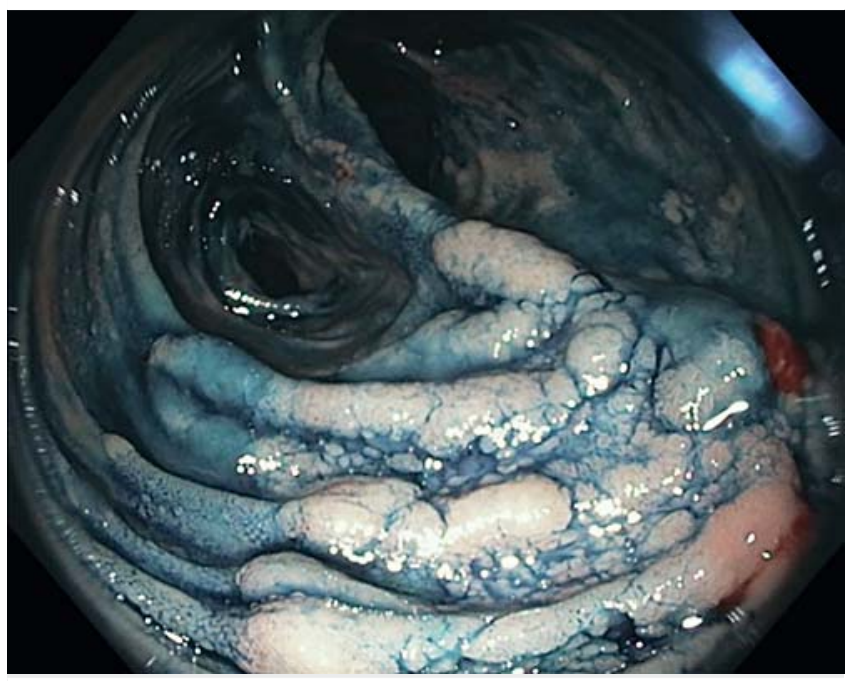

- Fig. 2 Same ileal pouch with multiple flat adenomas and indigocarmine dye showing numerous large flat adenomas.

presents standards of care in our center, there was no need for an ethical committee approval.

\section{Study endpoints}

The primary objective was to describe the impact of a preferred rectal preservation strategy, associated with systematic endoscopic treatment of the remnant, on secondary rectal or J pouch cancer occurrence. In this setting, the number of lesions detected and treated during surveillance (i. e. polyp count) was reported and compared between IRA and IAA groups. Histological staging used the Union Internationale Contre le Cancer/ TNM classification, seventh edition [7]. Secondary objectives included the description of 15 and 25 years overall and cancerfree survival. The description of morbidity related to surgery or to endoscopy. Morbidity was assessed according to surgical classifications [8]. Long-term morbidity was also evaluated

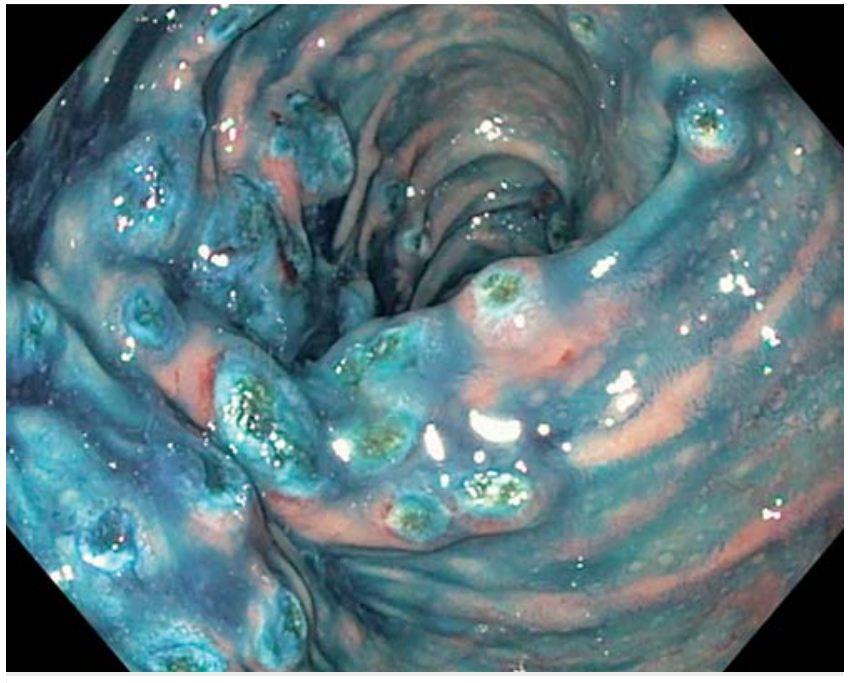

Fig. 3 Rectal aspect after APC treatment of numerous polyps.

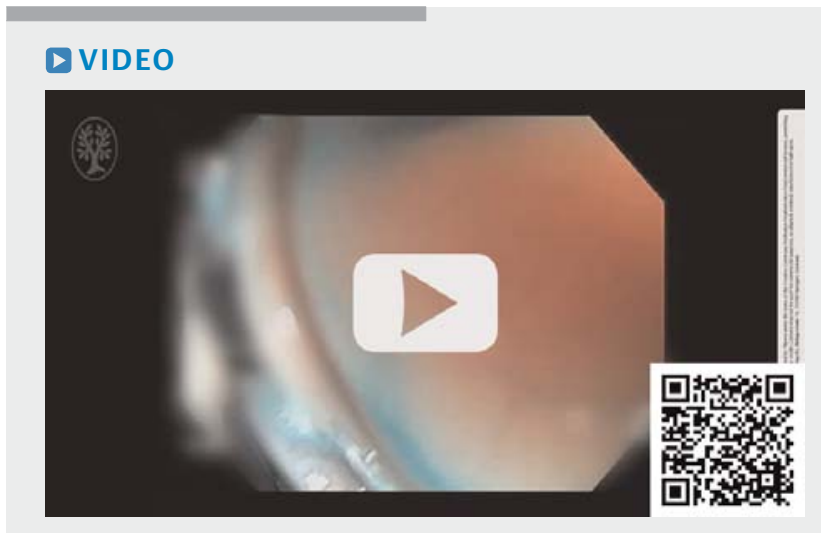

- Video 1 This video shows endoscopic treatment of numerous adenomas (most visible lesions after indigo-carmine dye) in the rectal stump of a polyposis patient using Argon Plasma Coagulation (APC).

through surgical complications: poor nutrition, sepsis, stenosis, and short bowel syndrome. Regarding Quality of life, we used indirect comparison of quality-of-life through mean number of stools per day and incontinence (Jorge \& Wexner score $\geq 5$ of 20 [9] and nocturnal leakage occurrence); values of the last available visit were considered.

\section{Statistical analysis}

The Student's $t$-test was used for intergroup comparisons of quantitative variables, and the $\mathrm{x} 2$ test or the Fisher tests to compare categorical data. Survival description was performed using Kaplan-Meier. All tests were 2-sided. For multiple tests, Bonferroni adjustment was applied to all tests and the interpretation of results were performed according to this adjustment for all datas. Statistical analyses were performed using Statistical Package for the Social Sciences v19.0 (SPSS, Chicago, Illinois, United States). 


\section{Results}

\section{Characteristics}

Between January 1965 and November 2015, 316 patients underwent prophylactic and/or curative surgery for FAP in Lyon Grenoble, and Saint Etienne University hospital. Two patients were excluded because of synchronous metastases, 18 because of the lack of endoscopic follow-up data. Among the remaining 296 patients, procedures consisted of proctocolectomy with IAA and J pouch ( $\mathrm{n}=92 ; 31.1 \%)$, total colectomy with IRA ( $\mathrm{n}=$ $197 ; 66.5 \%$ ), and proctocolectomy with abdominoperineal resection (APR) and definitive ileostomy $(n=7 ; 2.3 \%)$. The seven patients with APR were excluded because no lower endoscopic follow-up was performed. The study population, therefore, included a total of 289 patients (92 with IAA and 197 with IRA). The sex ratio was 0.9:1. The mean (SD) age was 29.5 (16.3) years ( $\triangleright$ Table 1 ). Ninety-five patients (32.9\%) had a previous history of digestive disease (surgical history and/or medical history $n=58 ; 20.1 \%)$, metabolic disease $(n=70 ; 24.2 \%)$, and cardiovascular disease $(n=51 ; 17.6 \%)$. All comorbidities were balanced between groups, except for metabolic comorbidities that were more frequent among patients in the IRA group than in the IAA group $(P=0.001)$. The most frequent genetic mutation was found on Exon 15 of the APC gene ( $n=96 ; 34.1 \%$; - Table 1).

Rectal adenoma count was detailed for most patients. A minority $(n=10 ; 3.3 \%)$ did not have a detailed colonic adenoma count. In preoperative workup, the mean (SD) number of colonic adenomas was 303.5 (269.6) in the IRA group and 334.4 (294.9) in the IAA group, $(P=0.82)$. The mean (SD) number of rectal adenomas was 24.7 (33.9) in the IRA group vs. 52.8 (27.8) in the IAA group ( $P=0.0001)$. Before surgery, primary colorectal cancer was found in 28 patients (9.7\%); 21 (10.7\%) in the IRA group, $7(7.6 \%)$ in the IAA group $(P=0.19 ;[95 \% \mathrm{Cl}$ $0.1-0.91])$. In those 28 patients, the repartition of primary cancers was as follows: primary rectal cancer was found in nine patients (3.1\%): $3(1.5 \%)$ in the IRA group (for these three patients, the rectum was preserved as the cancer was intramucosal and completely treated at endoscopy) and six (6.5\%) in the IAA group $(P=0.0001)$.

\section{Secondary cancer on rectal stump or ileal J pouch.}

The median follow-up was 17.1 [0-38.1] years. Secondary cancer characteristics are listed in $>$ Table 2 . Secondary cancer occurred in 13 patients: 12 patients (6.1\%) in the IRA group and one (1.1\%) in the IAA group (Vienna 4.2). Ten of 12 rectal cancers were diagnosed at first endoscopy in our center. The 2 other rectal cancers occurred during the follow up: one despite regular follow-up (intramucosal cancer, Vienna 4.2) and the second was a T1 cancer diagnosed after a large interruption of follow up (Vienna 4.2). Three cancers in the IRA group were classified T1 but after pathological examination, one was T1 and Two Tis (2 intramucosal adenocarcinomas Vienna 4.2) which were exclusively treated by an endoscopic $\mathrm{R} 0$ resection. The mean interval between surgery and rectal or pouch secondary cancer was 272 months (22.6 years; - Table 3 ). Ten of 12 rectal cancers underwent secondary proctectomy (5 IAA and 5 APR). The mean (SD) number of rectal/pouch adenomas found at each endoscopy was of 22.7 (27.7) in those with secondary cancer vs. 22.1 (29.8) in those without. The mean (SD) number of adenomas treated at each endoscopy was of 16.9 (14.4) in those with secondary cancer vs. 16.1 (20.4) in those without.

\section{Survival}

The 15-year cancer-free survival was of $99.5 \%$ in the IRA group and $100 \%$ in the IAA; the 25 -year cancer-free survival was of $96.3 \%$ in the IRA group and $98 \%$ in the IAA group.

The mean cancer-free survival in the IRA group was 46.55 years $(95 \% \mathrm{Cl} 48.12-51.1)$ and 46.5 years $(95 \% \mathrm{Cl} 43.4-49.7)$ in the IAA group $(P=0.16)$. The 15 -year overall survival was $98.9 \%$ in IRA group and $98.8 \%$ in IAA group; the 25 -year overall survival was $97.8 \%$ in the IRA group and $98.8 \%$ in the IAA group. The mean overall survival in the IRA group was 50 years $(95 \% \mathrm{Cl}$ $47.5-80.8)$ and 49 years $(95 \% \mathrm{Cl} 48.6-52.1)$ in the IAA group $(P=0.69)$.

\section{Postoperative morbidity}

Postoperative morbidity occurred in 44 patients (15.2\%); 29 patients $(14.7 \%)$ of the IRA group and 15 (16.3\%) of the IAA group $(P=0.72$ (95\% Cl $0.5-0.79)$; Table 3$)$. The majority of complications were low-grade complications. Severe post-operative complications were observed in 3 patients $(1.5 \%)$ in the IRA group vs. 2 patients $(2.2 \%)$ in the IAA group $(P=0.65$ [ $95 \% \mathrm{Cl} 0.05-0.85])$. Redo surgery was performed in $4.1 \%$ of the IRA group vs. $4.3 \%$ of the IAA group $(P=0.91(95 \% \mathrm{Cl} 0.34-$ $0.94)$. Long-term morbidity occurred in 48 patients $(24.4 \%)$ in the IRA group vs. $37(40.2 \%)$ in the IAA group $(P=0.006[95 \% \mathrm{Cl}$ 0.001-0.02]). There was no case of chronic leakage in the IRA group vs. $6.5 \%(n=6)$ in the IAA group $(P=0.001[95 \% \mathrm{Cl}$ 0.001-0.01]) (> Table 3).

\section{Endoscopic follow-up, treatment, and induced morbidity}

Endoscopic follow-up was complete for 179 patients (90.9\%) in the IRA group and $84(91.3 \%)$ in the IAA group $(P=0.90)$. The mean (SD) number of lower endoscopies performed was respectively $4.4(3.5)$ and $4.4(3.5 ; P=0.91)$. The mean (SD) number of treated adenomas at each endoscopic session was of 17.8 (20.8) in the IRA group vs. $12.9(18.8)$ in the IAA group $(P=0.06)$. At least one endoscopic complication occurred in 90 patients $(45.7 \%)$ in the IRA group vs. $52(56.5 \%)$ in the IAA group $(P=0.08)$ during this long-term follow-up.In case of post-procedural complication, conservative treatment was possible in $98.8 \%$ of patients in the IRA group vs. $100 \%$ of the IAA group; surgery was required in $0.5 \%$ of patients in the IRA group vs. none in the IAA group, and a redo endoscopy for complication treatment was required in $0.5 \%$ of patients in the IRA group vs. $2.2 \%$ in the IAA group ( $>$ Table 4 ). The percentage of patients presenting with at least on episode of bleeding related to endoscopic treatment during the follow-up was $16.8 \%$ in the IRA group and $15.2 \%$ in the IAA group. 
- Table 1 Patient characteristics

\begin{tabular}{|c|c|c|c|c|}
\hline & Sample population & IRA & IAA & \multirow[t]{2}{*}{$P$ value } \\
\hline & $n=289$ & $n=197$ & $n=92$ & \\
\hline Age, (mean (SD)) & $29.5(16.3)$ & $31.9(18)$ & $24.3(9.6)$ & 0.0001 \\
\hline \multicolumn{5}{|l|}{ Sex, n (\%) } \\
\hline Male & $138(47.8)$ & $95(48.2)$ & $43(46.7)$ & \multirow{2}{*}{0.81} \\
\hline Female & $151(52.2)$ & $102(51.8)$ & $49(53.3)$ & \\
\hline \multicolumn{5}{|l|}{ Mutation, n (\%) } \\
\hline Exon 15 & $96(33.2)$ & $55(27.9)$ & $41(44.6)$ & 0.005 \\
\hline Other mutations & $86(29.7)$ & $57(28.9)$ & $29(31.5)$ & 0.69 \\
\hline Missing & $107(37.1)$ & $85(43.2)$ & $22(23.9)$ & \\
\hline \multicolumn{5}{|l|}{ Comorbidities, n (\%) } \\
\hline \multicolumn{5}{|l|}{ Smoking } \\
\hline Never & $221(76.5)$ & $148(75.1)$ & $73(79.3)$ & \multirow{3}{*}{0.28} \\
\hline Previous & $53(18.3)$ & $13(6.6)$ & $2(2.2)$ & \\
\hline Current & $15(5.2)$ & $36(18.3)$ & $17(18.5)$ & \\
\hline Pulmonary & $31(10.7)$ & $21(10.7)$ & $10(10.9)$ & 0.96 \\
\hline Cardiovascular & $51(17.6)$ & $39(19.8)$ & $12(13.0)$ & 0.16 \\
\hline Neurologic & $30(10.4)$ & $19(9.6)$ & $11(12.0)$ & 0.55 \\
\hline Hematologic & $7(2.4)$ & $6(3.0)$ & $1(1.1)$ & 0.31 \\
\hline Desmoid tumor, n (\%) & $38(13.1)$ & $22(11.2)$ & $16(17.4)$ & 0.14 \\
\hline Number of preoperative colic adenomas (mean (SD)) & $316.5(278.7)$ & $303.5(269.6)$ & $334.4(294.9)$ & 0.82 \\
\hline Number of preoperative rectal adenomas (mean (SD)) & $34.1(34.6)$ & $24.7(33.9)$ & $52.8(27.8)$ & 0.0001 \\
\hline \multicolumn{5}{|l|}{ Adenocarcioma at diagnosis, $\mathrm{n}(\%)$} \\
\hline Colorectal & $28(9.7)$ & $21(10.7)$ & $7(7.6)$ & 0.41 \\
\hline Rectal & $9(3.1)$ & $3(1.5)$ & $6(6.5)$ & 0.02 \\
\hline \multicolumn{5}{|l|}{ Operative technique, n (\%) } \\
\hline Laparoscopy & $97(34.6)$ & $89(45.2)$ & $8(8.7)$ & \multirow{2}{*}{0.0001} \\
\hline Open & $192(65.4)$ & $108(54.8)$ & $84(91.3)$ & \\
\hline
\end{tabular}

\section{Quality-of-life}

At the end of follow-up, the median age in the IRA group was 52 years [35.1-68.9] and 42.5 [30.4-54.6] in the IAA group. The mean (SD) number of stools per day (including night-time) was $4.4(2.5)$ in the IRA group vs. $5.5(2.6)$ in the IAA group ( $P$ $=0.001)$. Fecal incontinence occurred in 14 patients $(7.1 \%)$ in the IRA group vs. $16(17.4 \%)$ in the IAA group $(P=0.03)$; 13 patients (6.6\%) suffered from nocturnal leakage in the IRA group vs. $20(23.5 \%)$ in the IAA group $(P=0.0001$; $>$ Table 3$)$.

\section{Discussion}

The main limit of the extended rectal preservation strategy is the difficulty to treat patients curatively without increasing long-term oncological risk. Guidelines for prophylactic surgery in FAP patients [1,2] were defined using thresholds for secondary rectal cancer risk reported in observational populationbased studies [2, 3, 10-13]. The latter did not include intensive interventional follow-up, and, although the concept of systematic endoscopic treatment of rectal or pouch adenomas is reported, thresholds are undefined [9]. Furthermore, it is suggested in guidelines that a higher number of lower endoscopies will be required after rectal preservation, as compared to pa- 
Table 2 Description of secondary cancers

\begin{tabular}{|c|c|c|c|c|c|c|c|c|c|}
\hline $\begin{array}{l}\text { Pa- } \\
\text { tient } \\
\text { no. }\end{array}$ & $\begin{array}{l}\text { Age at } \\
\text { primary } \\
\text { surgery }\end{array}$ & Group & $\begin{array}{l}\text { Age at di- } \\
\text { agnosis } \\
\text { of sec- } \\
\text { ondary } \\
\text { cancer }\end{array}$ & $\begin{array}{l}\text { Number of } \\
\text { pretreat- } \\
\text { ment endos- } \\
\text { copy reports } \\
\text { available }\end{array}$ & $\begin{array}{l}\text { Time } \\
\text { since last } \\
\text { endos- } \\
\text { copy } \\
\text { (mo) }\end{array}$ & $\begin{array}{l}\text { Findings in } \\
\text { previous } \\
\text { procedures }\end{array}$ & $\begin{array}{l}\text { Endoscopic/sur- } \\
\text { gical treatment }\end{array}$ & $\begin{array}{l}\text { Patholo- } \\
\text { gy }\end{array}$ & $\begin{array}{l}\text { Vienna } \\
\text { classifi- } \\
\text { cation }\end{array}$ \\
\hline 1 & 13 & IAA & 30 & 1 & 1 & & $\begin{array}{l}\text { Endoscopic mu- } \\
\text { cosectomy }\end{array}$ & $\mathrm{T}$ is & 4.2 \\
\hline 2 & 49 & IRA & 70 & 0 & & & $\begin{array}{l}\text { Abdominoperi- } \\
\text { neal resection }\end{array}$ & $\begin{array}{l}\text { Not avail- } \\
\text { able }\end{array}$ & \\
\hline 3 & 28 & IRA & 50 & 4 & 36 & $\begin{array}{l}\text { High-grade } \\
\text { dysplasia }\end{array}$ & $\begin{array}{l}\text { Abdominoperi- } \\
\text { neal resection }\end{array}$ & $\mathrm{T}$ is & 4.2 \\
\hline 4 & 15 & IRA & 50 & 1 & 0 & $\begin{array}{l}\text { Adenocarci- } \\
\text { noma }\end{array}$ & $\begin{array}{l}\text { Abdominoperi- } \\
\text { neal resection }\end{array}$ & T3N0M0 & \\
\hline 5 & 21 & IRA & 24 & 5 & 6 & $\begin{array}{l}\text { High-grade } \\
\text { dysplasia }\end{array}$ & Ileoanal pouch & $\begin{array}{l}\text { Not avail- } \\
\text { able }\end{array}$ & \\
\hline 6 & 54 & IRA & 54 & 0 & & & $\begin{array}{l}\text { Abdominoperi- } \\
\text { neal resection }\end{array}$ & $\begin{array}{l}\text { Not avail- } \\
\text { able }\end{array}$ & \\
\hline 7 & 41 & IRA & 70 & 0 & & & $\begin{array}{l}\text { Abdominoperi- } \\
\text { neal resection }\end{array}$ & $\begin{array}{l}\text { Not avail- } \\
\text { able }\end{array}$ & \\
\hline 8 & 24 & IRA & 44 & 0 & & & $\begin{array}{l}\text { Abdominoperi- } \\
\text { neal resection }\end{array}$ & T4N1M0 & \\
\hline 9 & 38 & IRA & 54 & 0 & & & $\begin{array}{l}\text { Abdominoperi- } \\
\text { neal resection }\end{array}$ & $\begin{array}{l}\text { Not avail- } \\
\text { able }\end{array}$ & \\
\hline 10 & 20 & IRA & 48 & 0 & & & $\begin{array}{l}\text { Abdominoperi- } \\
\text { neal resection }\end{array}$ & T2N0M0 & \\
\hline 11 & 39 & IRA & 56 & 0 & & & Ileoanal pouch & $\begin{array}{l}\text { Not avail- } \\
\text { able }\end{array}$ & \\
\hline 12 & 27 & IRA & 50 & 0 & & & Ileoanal pouch & $\begin{array}{l}\text { Not avail- } \\
\text { able }\end{array}$ & \\
\hline 13 & 27 & IRA & 71 & 3 & 6 & $\begin{array}{l}\text { High-grade } \\
\text { dysplasia }\end{array}$ & $\begin{array}{l}\text { Abdominoperi- } \\
\text { neal resection }\end{array}$ & $\mathrm{T}$ is & 4.2 \\
\hline
\end{tabular}

tients with IA anastomosis and J pouch, and that the constraints of repeated intrusive investigation mean that treatment success will be determined by patient willingness to submit to a close follow-up [1,2]. Nevertheless, recent guidelines regarding endoscopic follow up defined surveillance interval according to phenotype, and proposed to increase these intervals in patients with a slower evolution [14,15]. Furthermore, each cancer occurred in patients who were not willing to accept close endoscopic follow up. With regard to oncological outcomes, it is of note that in the present study, the incidence of secondary rectal cancer after extended indications for rectal preservation were much lower than that previously reported (i. e. $13 \%$ to $59 \%$ at 25 years of follow-up $[3,16,17])$. Furthermore, the factors reported to be associated with rectal secondary cancer occurrence in the literature are a longer length of conserved rectum $(>7 \mathrm{~cm})$, age $>44$ years, and profuse preoperative polyposis ( $>500$ colonic adenomas and $>20$ rectal adenomas) $[3,4]$. In the present cohort, however, neither increased age nor the number of preoperative/postoperative adenomas during follow-up was found to be associated with secondary rectal cancer (length of conserved rectum was not systematically reported). These results are in keeping with the therapeutic strategy proposed, whereby a large number of even small adenomas was systematically treated during endoscopy, which also impacts the risk of secondary proctectomy that was far lower than previously reported in the literature $35 \%$ when $>20$ rectal adenomas are found at diagnosis [18], and 70\% 40 years after first surgery) [19].

Herein, only one case of secondary cancer in the ileal J pouch was found. The risk of pouch cancer was formerly underrecognized, but is now described and accepted [1,2]. According to guidelines [1,2], this number of lower endoscopies was justified by the need of pouch follow-up due to the risk of secondary pouch cancer development [9,20-24]. For instance, in a systematic review that included 18 papers, six studies reported newly-developed adenocarcinomas of the ileal J pouch, and 
- Table 3 Postoperative data

\begin{tabular}{|c|c|c|c|}
\hline & IRA & IAA & \multirow[t]{2}{*}{$P$ value } \\
\hline & $n=197$ & $n=92$ & \\
\hline Mean length of stay, (mean (SD)) & $8.7(4.8)$ & $7.9(2.8)$ & 0.14 \\
\hline Postoperative morbidity, n (\%) & $29(14.7)$ & $15(16.3)$ & 0.72 \\
\hline Long-term morbidity, n (\%) & $48(24.4)$ & $37(40.2)$ & 0.006 \\
\hline Poor nutrition & $8(4.1)$ & $3(3.3)$ & 0.74 \\
\hline Short bowel length & $3(1.5)$ & $4(4.3)$ & 0.21 \\
\hline Prolapse & 0 & $1(1.1)$ & 0.31 \\
\hline Deep abcess & $1(0.5)$ & 0 & 1 \\
\hline Ascitis & $1(0.5)$ & 0 & 1 \\
\hline Chronic leakage & 0 & $6(6.5)$ & 0.001 \\
\hline Bowel perforation related to desmoid tumor & 0 & $3(3.3)$ & 0.03 \\
\hline Peritonitis & $1(0.5)$ & $1(1.1)$ & 0.53 \\
\hline Bleeding & $2(1.0)$ & $3(3.3)$ & 0.17 \\
\hline Occlusion & $28(14.2)$ & $17(18.5)$ & 0.35 \\
\hline Anatomotic stenosis & $9(4.6)$ & $12(13.0)$ & 0.01 \\
\hline Anal fissure & $1(0.5)$ & 0 & 1 \\
\hline Pouchitis & 0 & $1(1.1)$ & 0.49 \\
\hline Event rate & $10(5.1)$ & $5(5.4)$ & 0.89 \\
\hline Secondary rectal/pouch cancer, n (\%) & $12(6.1)$ & $1(1.1)$ & 0.06 \\
\hline Surgical treatment & $10(5.1)$ & 0 & \\
\hline IAA & $5(2.5)$ & 0 & \\
\hline APR & $5(2.5)$ & 0 & \\
\hline Endoscopic treatment mucosectomy & $2(1.0)$ & $1(1.1)$ & \\
\hline \multicolumn{4}{|l|}{ Pathology of secondary cancer, n (\%) } \\
\hline Intramucosal & $2(1.0)$ & $1(1.1)$ & \multirow{7}{*}{0.71} \\
\hline $\mathrm{T} 1$ & $1(0.5)$ & 0 & \\
\hline $\mathrm{T} 2$ & $2(1.0)$ & 0 & \\
\hline T3 & $2(1.0)$ & 0 & \\
\hline T4 & 0 & 0 & \\
\hline N1 & $1(0.5)$ & 0 & \\
\hline M & $1(0.5)$ & 0 & \\
\hline Carcinomatosis & $1(0.5)$ & 0 & 0.20 \\
\hline Pelvic recurrence & 0 & $1(1.1)$ & 0.21 \\
\hline \multicolumn{4}{|l|}{ Quality of life, n (\%) } \\
\hline Number of stools per day (mean (SD)) & $4.4(2.5)$ & $5.5(2.6)$ & 0.001 \\
\hline Incontinence & $14(7.1)$ & $16(17.4)$ & 0.03 \\
\hline Nocturnal leakage & $13(6.6)$ & $20(23.5)$ & 0.0001 \\
\hline
\end{tabular}


- Table 4 Endoscopic follow-up and induced morbidity.

\begin{tabular}{|c|c|c|c|}
\hline & IRA & IAA & \multirow[t]{2}{*}{$P$ value } \\
\hline & $n=197$ & $n=92$ & \\
\hline \multicolumn{4}{|l|}{ Endoscopic follow-up, n (\%) } \\
\hline Yes & $179(90.9)$ & $84(91.3)$ & \\
\hline No & $18(9.1)$ & $8(8.7)$ & 0.90 \\
\hline Number of lower endoscopy (mean (SD)) & $4.4(3.5)$ & $4.4(3.5)$ & 0.91 \\
\hline Total number of adenomas per patient & $95.6 \pm 140.3$ & $84.8 \pm 139.9$ & 0.56 \\
\hline Total number of treated adenomas per patient & $74 \pm 103.8$ & $55.1 \pm 97.7$ & 0.15 \\
\hline Mean number of adenomas per endoscopy & $23.7 \pm 32.2$ & $19.2 \pm 23.9$ & 0.20 \\
\hline Mean number of treated adenomas per endoscopy & $17.8 \pm 20.8$ & $12.9 \pm 18.8$ & 0.06 \\
\hline Endoscopic morbidity, n (\%) & $90(45.7)$ & $52(56.5)$ & 0.08 \\
\hline Anesthesia & $8(4.1)$ & $4(4.3)$ & 0.90 \\
\hline Perforation & $3(1.5)$ & $2(2.2)$ & 0.65 \\
\hline Pain & $14(7.1)$ & $7(7.6)$ & 0.33 \\
\hline Acute bleeding & $33(16.8)$ & $14(15.2)$ & 0.74 \\
\hline \multicolumn{4}{|l|}{ Treatment for endoscopic complication, n (\%) } \\
\hline Transfusion & $3(1.5)$ & $4(4.3)$ & 0.21 \\
\hline Surgery & $1(0.5)$ & $0(0)$ & 1 \\
\hline Redo endoscopy & $1(0.5)$ & $2(2.2)$ & 0.29 \\
\hline
\end{tabular}

half were advanced tumors (T4) [23]. Furthermore, Tonelli et al. reported a low incidence of pouch adenocarcinoma (2 of 66) in a prospective cohort of IAA patients, but noted faster pathophysiological development compared to adenomas [25]. This underscores the importance of endoscopic follow-up for IAA patients. One of the arguments against extensive rectal preservation has been the more frequent endoscopy required, but it is of note that in our experience the mean number of indicated lower endoscopies was the same in the IRA and IAA groups. The respective bleeding rate after endoscopic treatment were $16.8 \%$ in the IRA group and $15.2 \%$ in the IAA group. Those bleeding rate can appear higher than usual morbidity described especially since laser/APC development. This relatively frequent event may be explained by the frequent use of APC with relatively frequent immediate and delayed bleeding in this situation.

It is usually accepted that quality of life is higher after IRA than after IAA [2]. These findings are based on several studies and systematic reviews $[15,26-32]$, which considered the mean number of stools per day, developed incontinence to gas or feces, and social life impairment. The results of the present study are consistent with previous findings: a significantly lower mean number of stools per day and less frequent fecal incontinence in patients of the IRA group compared to those in the IAA group. These results also favor rectal preservation when feasible. Combined with the positive oncological outcomes induced by aggressive and intense endoscopic treatment of remaining/newly-developed rectal adenomas, the evolution towards systematic rectal preservation appears to be a safe and feasible alternative to improve quality of life without compromising outcomes.

The strengths of the present study include its large sample size for this rare disease, and the inclusion of patients from a national collaborative network with comparable modalities of endoscopic follow-up and treatment. It does, however, have potential limitations related to its (partly) retrospective nature. As with all such cohorts, the present results would have been exposed to selection bias, yet the impact of this is likely to have been limited as all patients with available data were analyzed. In addition, owing to its retrospective nature, no power calculation was performed but the study does represent a large dedicated series to evaluate the oncological outcomes of this rare disease. Finally, although no definitive conclusions can be made, this study provides interesting results on which to base future collaborative, multicentric controlled trials. 


\section{Conclusions}

The combination of aggressive endoscopic treatment and extended rectal preservation appears to be a safe alternative to ileoanal anastomosis and J pouch, which may modify surgical choices and quality of life in FAP patients. Further prospective studies evaluating this combined therapeutic strategy are needed to validate these results and to revise guidelines.

\section{Competing interests}

The authors declare that they have no conflict of interest.

\section{References}

[1] Church ], Clifford S. Practice parameters for the treatment of patients with dominantly inherited colorectal cancer. Dis Colon Rectum 2003; 46: 1001-1012

[2] Institut national du cancer. Chirurgie prophylactique des cancers avec prédisposition génétique [Internet]. 2009: Available from: https:// www.e-cancer.fr/content/download/58351/531984/file/chir_prophy_predi_gene_polypose.pdf

[3] Iwama T, Mishima Y. Factors influencing rectum-preserving surgery in patients with familial adenomatous polyposis. Dis Colon Rectum 1994; 37: 1024-1026

[4] Sinha A, Tekkis PP, Rashid S et al. Risk factors for secondary proctectomy in patients with familial adenomatous polyposis. Br J Surgery 2010; 97: 1710-1715

[5] Plateforme d'échange entre les professionnels de santé (PEPS). https://peps.sante-ra.fr

[6] Saurin JC, Napoleon B, Gay G et al. Endoscopic management of patients with familial adenomatous polyposis (FAP) following a colectomy. Endoscopy 2005; 37: 499-501

[7] UICC TNM classification of malignant tumors. 7th ed. New York: Wiley-Blackwell; 2009

[8] Dindo D, Demartines N, Clavien P-A. Classification of surgical complications. Ann Surgery 2004; 240: 205-213

[9] Jorge JM, Wexner SD. Etiology and management of fecal incontinence. Dis Colon Rectum 1993; 36: 77-97

[10] Church J, Burke C, McGannon E et al. Risk of rectal cancer in patients after colectomy and ileorectal anastomosis for familial adenomatous polyposis: a function of available surgical options. Dis Colon Rectum 2003; 46: 1175-1181

[11] Jarvinen HJ. Time and type of prophylactic surgery for familialadenomatosis coli. Ann Surgery 1985; 202: 93-97

[12] Debinski HS, Love S, Spigelman AD et al. Colorectal polyp counts and cancer risk in familial adenomatous polyposis. Gastroenterol 1996; 110: $1028-1030$

[13] Church JM, McGannon E, Burke C et al. Teenagers with familial adenomatous polyposis: what is their risk for colorectal cancer? Dis Colon Rectum 2002; 45: 887-889

[14] Van Leerdam ME, Roos VH, Van Hooft JE et al. Endoscopic management of polyposis syndromes: European Society of Gastrointestinal Endoscopy (ESGE) Guideline. Endoscopy 2019; 51: 877-895
[15] Monahan KJ, Bradshaw N, Dolwani S et al. Guidelines for the management of hereditary colorectal cancer from the British Society of Gastroenterology (BSG)/Association of Coloproctology of Great Britain and Ireland (ACPGBI)/United Kingdom Cancer Genetics Group (UKCGG). Gut 2020; 69: 411-444

[16] Vasen HF, Van der luijt RB, Slors JF. Molecular genetic tests as a guide to surgical management of familial adenomatous polyposis. Lancet 1996; 348: 433-435

[17] Bülow S, Bülow C, Vasen $\mathrm{H}$ et al. Colectomy and ileorectal anastomosis is still an option for selected patients with familial adenomatous polyposis. Dis Colon Rectum 2008; 51: 1318-1323

[18] Church J, Burke C, Gannon EM et al. Predicting polyposis severity by proctoscopy: how reliable is it? Dis Colon Rectum 2001; 44: 12491254

[19] Arvanitis ML, Jagelman DG, Fazio VW et al. Mortality in patients with familial adenomatous polyposis. Dis Colon Rectum 1990; 33: 639642

[20] Vrouenraets BC, Van Duijvendijk P, Bemelman WA et al. Adenocarcinoma in the Anal canal after ileal pouch-anal anastomosis for familial adenomatous polyposis using a double-stapled technique: report of two cases. Dis Colon Rectum 2004; 47: 530-534

[21] Duff SE, ODwyer ST, Hulten L et al. Dysplasia in the ileoanal pouch. Colorect Dis 2002; 4: 420-429

[22] Tonelli F, Ficari F, Bargellini T et al. Ileal pouch adenomas and carcinomas after restorative proctocolectomy for familial adenomatous polyposis. Dis Colon Rectum 2012; 55: 322-329

[23] Church J. Ileoanal pouch neoplasia in familial adenomatous polyposis: an underestimated threat. Dis Colon Rectum 2005; 48: 1708-1713

[24] Moussata D, Nancey S, Lapalus M et al. Frequency and severity of ileal adenomas in familial adenomatous polyposis after colectomy. Endoscopy 2008; 40: 120-125

[25] Hassan I, Chua HK, Wolff BG et al. Quality of life after ileal pouch-anal anastomosis and ileorectal anastomosis in patients with familial adenomatous polyposis. Dis Colon Rectum 2005; 48: 2032-2037

[26] Osterfeld N, Kadmon M, Brechtel A et al. Preoperative and postoperative quality of life in patients with familial adenomatous polyposis. Dis Colon Rectum 2008; 51: 1324-1330

[27] Douma KFL, Bleiker EMA, Vasen HFA et al. Quality of life and consequences for daily life of familial adenomatous polyposis (FAP) family members. Colorect Dis 2010; 13: 669-677

[28] Wolf ND, Kadmon M, Wolf RC et al. Quality of life after restorative proctocolectomy and ileal pouch-anal anastomosis in patients with familial adenomatous polyposis: a matter of adjustment. Colorect Dis 2011; 13: e358-e365

[29] Durno CA, Wong J, Berk T et al. Quality of life and functional outcome for individuals who underwent very early colectomy for familial adenomatous polyposis. Dis Colon Rectum 2012; 55: 436-443

[30] Van Balkom KA, Beld MP, Visschers RG] et al. Long-term results after restorative proctocolectomy with ileal pouch-anal anastomosis at a young age. Dis Colon Rectum 2012; 55: 939-947

[31] Ganschow P, Pfeiffer U, Hinz U et al. Quality of life ten and more years after restorative proctocolectomy for patients with familial adenomatous polyposis coli. Dis Colon Rectum 2010; 53: 1381-1387

[32] Andrews L, Mireskandari S, Jessen J et al. Impact of familial adenomatous polyposis on young adults: quality of life outcomes. Dis Colon Rectum 2007; 50: 1306-1315 